\title{
Expression and Purification of Exposed Outer Domain of Pseudomonas aeruginosa Opr86 protein
}

\author{
Shradha Jamwal ${ }^{1,2}$ and Niraj K. Singh ${ }^{1 *}$ \\ ${ }^{1}$ College of Animal Biotechnology, Guru Angad Dev Veterinary and Animal Sciences University, Ludhiana, Punjab, INDIA \\ ${ }^{2}$ Animal Biotechnology Centre, National Dairy Research Institute, Karnal, Haryana, INDIA
}

"Corresponding author: Niraj K. Singh; E-mail: nirajvet57@gmail.com

Received: 14 June, 2021

Revised: 18 July, 2021

Accepted: 22 July, 2021

\begin{abstract}
Pseudomonas aeruginosa ( $P$. aeruginosa) is an opportunistic pathogen that can form a biofilm that provides crucial drug resistance components. The bacteria have many immunogenic outer membrane proteins (OMP) including, Opr86. The Opr86 is essential for the viability of bacterium, as it has a significant role in OMP assembly and its depletion leads to alteration of cellular morphology. Therefore, Opr86 may serve as a vaccine candidate. Moreover, Opr86 may be used for raising hyperimmune serum, which may be a potential therapeutic candidate in P. aeruginosa infection. In the current study, gene fragment encoded exposed outer domain toward extracellular side of Opr86 (E-Opr86) was amplified by polymerase chain reaction (PCR), cloned into pJET1.2 vector, and sequenced. The gene was inserted into pET302/NT-His vector and was expressed in Rosetta-gami 2(DE3) pLysS cells. The recombinant E-Opr86 protein expression was confirmed by the sodium dodecyl sulfate-polyacrylamide gel electrophoresis (SDS-PAGE) and subjected to purification using His-tag affinity chromatography. The purified protein $(\sim 18 \mathrm{kDa})$ was confirmed by SDS-PAGE and by the Western blotting. This study successfully cloned and characterized Opr86 protein of $P$. aeruginosa.
\end{abstract}

\section{HIGHLIGHTS}

0 Gene encoding exposed outer domain of Pseudomonas aeruginosa Opr86 (E-Opr86) protein was cloned and sequenced.

( Recombinant E-Opr86 protein of approximetlt $18 \mathrm{kDa}$ size was expressed and purifesd using bacterial expression system.

Keywords: Pseudomonas aeruginosa, biofilm, E-Opr86 protein

The Pseudomonas aeruginosa is a Gram-negative rodshaped bacteria (Furchtgott et al., 2011) belonging to Pseudomonas genus, Pseudomonadaceae family (Wu and Li, 2014). It is an opportunistic organism known for causing nosocomial infections like pneumonia, bacteremia and cystic fibrosis in immune-compromised individuals (Zhang et al., 2018). The therapy of this organism is tough due to antibiotic resistance (Pang et al., 2019) and low evident to the immune system (Alhede et al., 2014) provided by biofilm state of organism exists in the body. The biofilm is an organized community of cells embedded in an extracellular polysaccharide matrix and attached to a surface (Tashiro et al., 2008).

As $P$. aeruginosa is a Gram-negative bacterium, it has a cytoplasmic membrane and an outer membrane. The outer membrane has numerous outer membrane proteins (OMPs) like OprD, OprE, OprF, OprH, Opr86 (Hemamalini and Khare 2014). In $P$. aeruginosa, many OMPs have been investigated as possible targets for developing vaccine candidates (Solanki et al., 2019). Opr86 is essential for the viability of $P$. aeruginos $a$, as it has a significant role in OMP assembly and its depletion leads to alteration of cellular morphology of bacterium. In addition, the antibody against Opr86 inhibits biofilm formation of $P$.

How to cite this article: Jamwal, S. and Singh, N.K. (2021). Expression and Purification of Exposed Outer Domain of Pseudomonas aeruginosa Opr86 protein. J. Anim. Res., 11(04): 571-577.

Source of Support: None; Conflict of Interest: None (c) 9 
aeruginosa (Tashiro et al., 2008) indicated Opr86 would be a good target for the design of new antibiotics vaccine.

The Opr86 has a $\beta$-barrel structure with 14 transmembrane domains. The region between 630 and 752 amino acid residues of Opr86 formed exposed outer domain (E-Opr86) toward the extracellular side of $P$. aeruginosa (Tashiro et al., 2008). Therefore in the current study, E-Opr86 domain protein was expressed using a prokaryotic expression system.

\section{MATERIALS AND METHODS}

\section{Bacterial culture revival and genomic DNA isolation}

The freeze-dried bacterial culture of $P$. aeruginosa, microbial type culture collection and the gene bank (MTCC) number 3542 were procured from the Institute of Microbial Technology (IMTECH), Chandigarh. Freeze-dried bacterial culture was revived by overnight inoculation in Luria-Bertani (LB) broth at $37^{\circ} \mathrm{C}$. Revived bacterial were sub-cultured overnight in $5 \mathrm{ml} \mathrm{LB}$ broth. The genomic DNA from $P$. aeruginosa (strain MTCC3542) culture was isolated using the protocol described earlier (Sambrook and Russell, 2001). The purity and concentration of isolated DNA were checked by a spectrophotometer (NanoDrop, ThermoFisher, CA, USA) machine.

\section{Polymerase chain reaction (PCR) amplification of E-Opr86}

The partial Opr86 (E-Opr86) coding gene was amplified using a forward primer having EcoRI restriction enzyme (RE) site $\left(\mathrm{OPR}_{\mathrm{F}}\right.$ : 5' - ACGTGAATTCATTCCACACC GAGCTGGGCTA-3') and reverse primer having Xho I RE site $\left(\mathrm{OPR}_{\mathrm{R}}\right.$ : 5'- CGATCTCGAGCTTGATCCAG GTCAGGCCGA-3'). The reaction mixture $(50 \mu \mathrm{l})$ for E-Opr86 amplification was prepared to have $10 \mu \mathrm{l}$ of $5 \mathrm{X}$ Phusion HF buffer, $1 \mu \mathrm{l}(10 \mathrm{mM}) \mathrm{dNTPs}, 1 \mu \mathrm{l}$ (10 pmole) of each primers, $1 \mu \mathrm{l}(1.84 \mathrm{ng})$ of genomic DNA, $1 \mu \mathrm{l}$ of 2U Phusion Hot start II DNA Polymerase (MBI-Thermo Scientific, USA) and $35 \mu \mathrm{l}$ nuclease-free water. PCR cycling condition followed initial denaturation at $94^{\circ} \mathrm{C}$ for 5 min followed by 30 cycles each of denaturation $\left(94^{\circ} \mathrm{C}\right.$ for $1 \mathrm{~min})$, annealing $\left(57^{\circ} \mathrm{C}\right.$ for $\left.20 \mathrm{~s}\right)$ and extension $\left(68^{\circ} \mathrm{C}\right.$ for $1 \mathrm{~min}$ ) and a final extension at $68^{\circ} \mathrm{C}$ for $10 \mathrm{~min}$. The
PCR product was confirmed by running on $1.0 \%$ agarose gel prepared in 1.0X TAE buffer containing $1.0 \mu \mathrm{g} / \mathrm{ml}$ ethidium bromide. The sample was run at 100 volts for 45 min and visualized on ChemiDoc XRS gel documentation system (BioRad, Hercules, USA). A 100 bp plus ladder marker (Fermentas) was used as a standard for determining the tentative base pair (bp) size of the PCR product.

\section{Cloning and sequencing of E-Opr86 gene}

The PCR product of E-Opr86 was purified by a PCR cleanup kit (Qiagen). The purified PCR product was ligated into pJET1.2/blunt cloning vector (Fermentas, MA, USA) using T4 Ligase. The ligated product was transformed into DH5 $\alpha$ E. coli cells. Transformed cells were spread on an LB-agar plate with ampicillin $(100 \mu \mathrm{g} / \mathrm{ml})$. The LB-agar plate was incubated overnight at $37^{\circ} \mathrm{C}$. After growing of bacterial colonies, few colonies were selected and inoculated in LB broth (with ampicillin @ $100 \mu \mathrm{g} / \mathrm{ml}$ ) and kept overnight on a shaker incubator at $37^{\circ} \mathrm{C}$. Plasmid from overnight incubated bacterial culture was isolated (Sambrook and Russell, 2001). The recombinant cloning vectors (E-Opr86- pJET1.2/blunt) were characterized by EcoRI and XhoI restriction enzyme double digestion. Subsequently, the E-Opr86 gene was cloned, confirmed by sequencing, and submitted to GenBank, NCBI database. Further, gene sequence obtained in current study and other corresponding sequences of various $P$. aeruginosa isolates obtained fron GenBank, NCBI were used for estimation of percentage similarity/divergence in E-Opr86 gene of vaious isolates and for construction of phylogenetic tree using the Lasergene (version 11.2.1) software.

\section{Sub-cloning of E-Opr86 gene in a bacterial expression vector}

The E-Opr86 gene was sub-cloned into pET302/NT-His (Thermo Fisher Scientific) bacterial expression vector. For the sub-cloning of the E-Opr86 gene, the insert from recombinant E-Opr86- pJET1.2/blunt plasmid was released using enzymes EcoRI and XhoI restriction enzyme. At the same time, expression vector pET302/NTHis was also digested with the same set of enzymes. A Double digested insert and expression vector was ligated using T4 Ligase, and the ligated product was cloned into DH5 $\alpha$ E. coli cells. Confirmation of the presence and orientation of the insert in the recombinant expression 
vector (E-Opr86- pET302/NT-His) was done by colony PCR with a forward T7 promoter primer and a reversed gene-specific primer. Further, confirmation was carried out by EcoRI and XhoI double digestion of recombinant expression vector.

\section{Expression of recombinant E-Opr86 protein}

The recombinant E-Opr86- pET302/NT-His vector was transformed into E. coli Rosetta-gami 2(DE3) pLysS cells (Sigma-Aldrich, Novagen). One colony of Rosetta-gami 2(DE3) pLysS having recombinant expression vector was grown in shaker flasks at $37^{\circ} \mathrm{C}$, in LB broth medium containing $50 \mu \mathrm{g} / \mathrm{ml}$ ampicillin $34 \mu \mathrm{g} / \mathrm{ml}$ chloramphenicol until $\mathrm{OD}_{600}$ reached 0.6 . Then $0.1 \mathrm{mM}$ of isopropyl B-Dthiogalactopyranoside (IPTG) was added to the medium to induce E-Opr86 expression. At 0, 1, 2, 3, 4, 6 hrs and overnight after induction, $1 \mathrm{ml}$ cells were collected and centrifuged at $8,000 \mathrm{~g}$ for $10 \mathrm{~min}$, and cell pellets were harvested. Each cell pellets were lysed by resuspension of pellet in $30 \mu$ sample buffer (Laemmli, Sigma, Germany) followed by boiling for 5 minutes and ice cooling. Cell lysates were centrifuged at $12,000 \mathrm{~g}$ for $10 \mathrm{~min}$ for the removal of insoluble cell debris. Supernatant fractions obtained were run on $10 \%$ SDS-PAGE gel along with prestained protein molecular weight marker (Fermentas) and stained with Coomassie Brilliant Blue dye.

\section{Purification of recombinant protein}

Purification of recombinant E-Opr86 protein was carried out by Ni-NTA affinity chromatography. The IPTG induced $50 \mathrm{ml}$ bacterial culture after $6 \mathrm{hrs}$ of induction was centrifuged at $8,000 \mathrm{~g}$ for $10 \mathrm{~min}$, the supernatant was decanted, and bacterial pellet was further used for protein purification. The cell pellet was re-suspended in Ni-NTA lysis buffer (100 $\mathrm{mM} \mathrm{NaH}_{2} \mathrm{PO}_{4}, 10 \mathrm{mM}$ Tris-Cl, $8 \mathrm{M}$ Urea, and $\mathrm{pH} 8.0$ ) and subjected to sonication at ice condition on a $20 \mathrm{~s}$ burst cycle for $2 \mathrm{~min}$, followed by centrifugation to clarify the cell lysate. The supernatant was collected and mixed gently to Ni-NTA slurry for one hr at $4{ }^{\circ} \mathrm{C}$ to bind His-Tag containing recombinant E-Opr86 protein. The mixture was poured to a chromatography column and allowed to pack. The unbounded protein was allowed to come out along with lysis buffer. The packed Ni-NTA in the column was washed by $10 \mathrm{ml}$ of wash buffer (100 $\mathrm{mM} \mathrm{NaH} \mathrm{PO}_{4}, 10 \mathrm{mM}$ Tris-Cl, $8 \mathrm{M}$ Urea, and $\mathrm{pH}$ 6.3).
The recombinant protein was eluted using $2 \mathrm{ml}$ of elution buffer $\left(100 \mathrm{mM} \mathrm{NaH}_{2} \mathrm{PO}_{4}, 10 \mathrm{mM}\right.$ Tris-Cl, $8 \mathrm{M}$ Urea, and $\mathrm{pH} 4.5)$. The eluted solution was kept in a dialysis bag and dialyzed in Phosphate-buffered saline (PBS) to remove urea and other salts from the protein solution. Further, SDS-PAGE analysis and western blotting were done for reconfirmation of purified protein.

\section{RESULTS}

\section{Genomic DNA isolation}

Genomic DNA from P. aeruginosa culture was isolated. Subsequently, purity and concentration of isolated genomic DNA were estimated NanoDrop. The ratio of optical density (OD) values at 260 nanometer (nm) and 260 $\left(\mathrm{OD}_{260 / 280}\right)$ of genomic DNA was 1.84 . The concentration of genomic DNA was $205 \mathrm{ng} / \mu \mathrm{l}$.

\section{PCR amplification of E-Opr86 gene}

The E-Opr86 coding gene was amplified by PCR using forward and reverse primers with EcoRI and XhoI RE sites. For PCR reaction, high fidelity Phusion Hot start II DNA Polymerase kit of MBI-Thermo Scientific, USA was used. The amplified product was confirmed by $1.0 \%$ agarose gel electrophoresis. In addition, a specific single band of approximately $460 \mathrm{bp}$ was observed in agarose gel (Fig. 1).

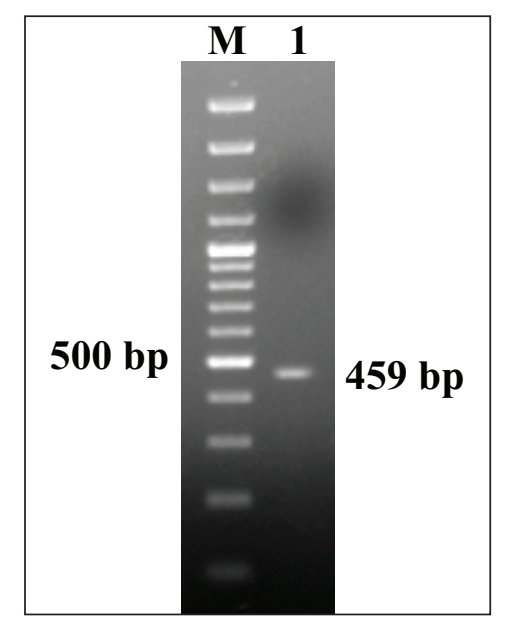

Fig. 1: PCR amplification of partial Opr86 (E-Opr86) gC gene of $P$. aeruginosa. Lane M: $100 \mathrm{bp}$ DNA Ladder plus marker, lane 1: amplified $E-O p r 86$ gene (459 bp) 
Cloning, sequencing and phylogenetic analysis of E-Opr86 gene

The purified PCR product of E-Opr86 was cloned into pJET1.2/blunt cloning vector. Recombinant cloning vectors (E-Opr86- pJET1.2/blunt) were characterized by EcoRI and XhoI double digestion. Double digestion produced two fragments of approximately $2974 \mathrm{bp} \mathrm{bp}$, and 459 bp (Fig. 2) confirmed the presence of E-Opr86 in the recombinant cloning vector. Subsequently, cloned E-Opr86 gene in recombinant cloning vector was sequenced, and the sequence was submitted to GenBank, NCBI (accession number: KF646784). Divergence analysis of E-Opr86 gene of various $P$. aeruginosa isolates indicated maximum $5.5 \%$ divergence among various isolates (Table 1 ).

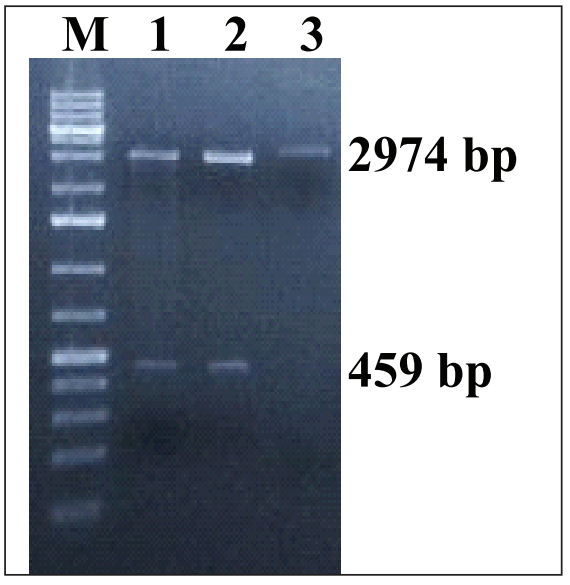

Fig. 2: Confirmation of E-Opr86 gene inserts in cloning vector by restriction enzyme digestion of recombinant plasmid. Lane M: O'GeneRuler $1 \mathrm{~kb}$ DNA Ladder, Lane 1 and 2: EcoRI/XhoI double digested plasmid, Lane 3: Uncut Plasmid

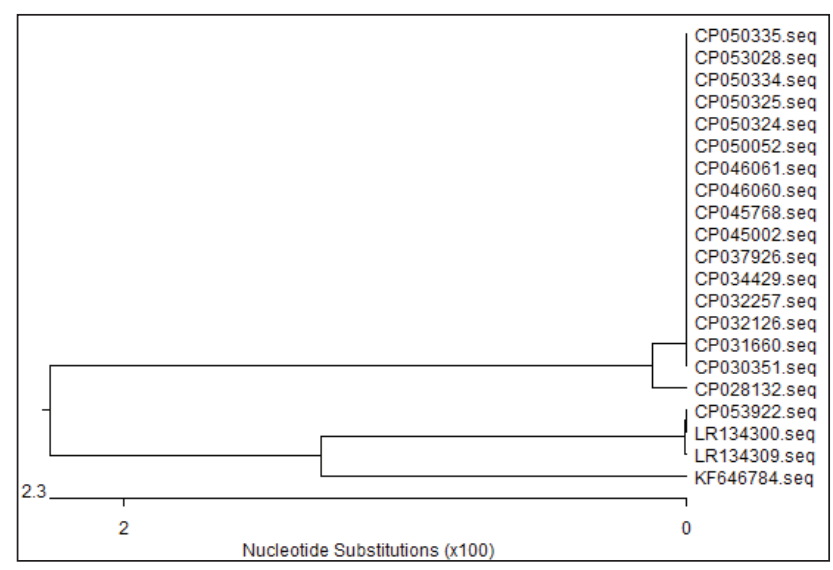

Fig. 3: Phylogentic tree based on E-Opr86 gene of various $P$. auriginosa isolates
Moreover, phylogentic analysis indicated gene used in this study was evolutionary closer to corresponding gene of isolates with accession number LR134300 and LR134309 (Fig. 3).

\section{Sub-cloning of E-Opr86 in a bacterial expression vector}

The E-Opr86 gene was sub-cloned into pET302/NT-His bacterial expression vector using $\mathrm{DH} 5 \alpha \mathrm{E}$. coli cells. Confirmation of the presence and orientation of the insert in the recombinant expression vector (E-Opr86- pET302/ NT-His) was done by colony PCR with forwarding T7 promoter primer and reversed gene-specific primer. Colony PCR gave an amplified product of approximately 500 bp (Fig. 4A). Further, confirmation was carried out by EcoRI and XhoI double digestion of recombinant expression vector. Double digestion produced two fragments of approximately $5700 \mathrm{bp}$, and $459 \mathrm{bp}$ (Fig. 4B) confirmed the presence and correct orientation of insert in the recombinant expression vector.

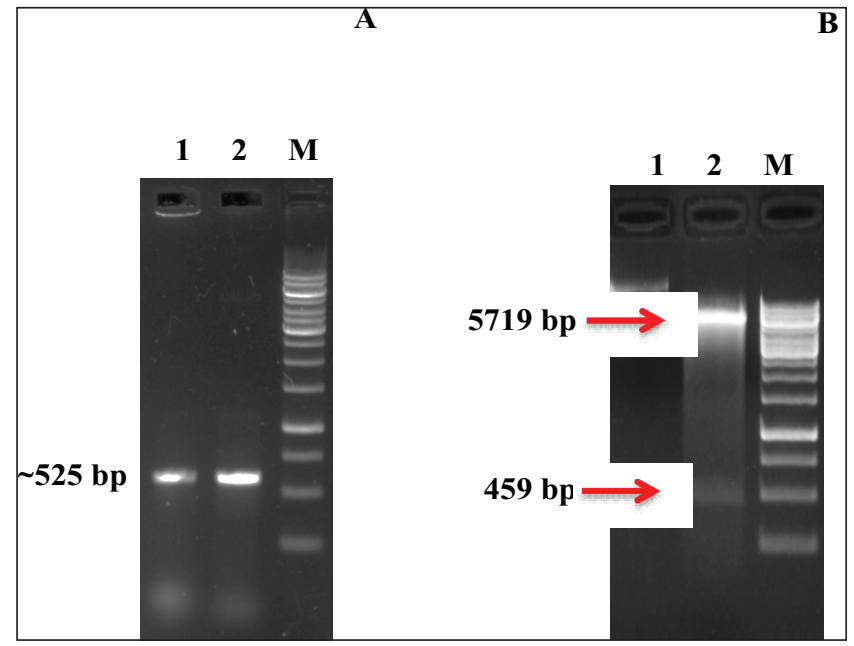

Fig. 4: Confirmation of E-Opr86 gene inserts in expression vector by (A) colony PCR of recombinant clone. Lane M: O'GeneRuler $1 \mathrm{~kb}$ DNA Ladder marker, Lane 1, 2: positive ampicillin-resistant E-Opr86- pET302/NT-His clone (B) restriction enzyme digestion of recombinant plasmid. Lane M: O'GeneRuler 1 kb DNA Ladder marker, Lane 1: Uncut Plasmid, Lane 2: EcoRI/XhoI double digested plasmid

\section{Expression of recombinant E-Opr86 protein}

The recombinant expression vector was isolated and transformed into E. coli Rosetta-gami 2(DE3) pLysS cells. 
Table 1: Percentage similarity/divergence in E-Opr86 gene of vaious $P$. auriginosa isolates

\begin{tabular}{|c|c|c|c|c|c|c|c|c|c|c|c|c|c|c|c|c|c|c|c|c|c|c|c|c|}
\hline \multicolumn{24}{|c|}{ Percent Identity } & \multirow[b]{3}{*}{ CP028132.seq } \\
\hline & & 1 & 2 & 3 & 4 & 5 & 6 & 7 & 8 & 9 & 10 & 11 & 12 & 13 & 14 & 15 & 16 & 17 & 18 & 19 & 20 & 21 & & \\
\hline \multirow{22}{*}{ 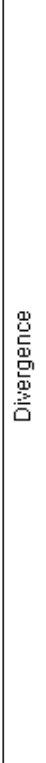 } & 1 & & 99.8 & 99.8 & 99.8 & 99.8 & 99.8 & 99.8 & 99.8 & 99.8 & 99.8 & 99.8 & 99.8 & 99.8 & 99.8 & 99.8 & 99.8 & 99.8 & 93.6 & 96.6 & 93.6 & 93.6 & 1 & \\
\hline & 2 & 0.2 & & 99.8 & 99.8 & 99.8 & 99.8 & 99.8 & 99.8 & 99.8 & 99.8 & 99.8 & 99.8 & 99.8 & 99.8 & 99.8 & 99.8 & 99.8 & 93.2 & 96.1 & 93.2 & 93.2 & 2 & CP030351.seq \\
\hline & 3 & 0.2 & 0.0 & & 100.0 & 100.0 & 100.0 & 100.0 & 100.0 & 100.0 & 100.0 & 100.0 & 100.0 & 100.0 & 100.0 & 100.0 & 100.0 & 100.0 & 93.4 & 96.3 & 93.4 & 93.4 & 3 & CP031660.seq \\
\hline & 4 & 0.2 & 0.0 & 0.0 & & 100.0 & 100.0 & 100.0 & 100.0 & 100.0 & 100.0 & 100.0 & 100.0 & 100.0 & 100.0 & 100.0 & 100.0 & 100.0 & 93.4 & 96.3 & 93.4 & 93.4 & 4 & CP032126.seq \\
\hline & 5 & 0.2 & 0.0 & 0.0 & 0.0 & & 100.0 & 100.0 & 100.0 & 100.0 & 100.0 & 100.0 & 100.0 & 100.0 & 100.0 & 100.0 & 100.0 & 100.0 & 93.4 & 96.3 & 93.4 & 93.4 & 5 & CP032257.seq \\
\hline & 6 & 0.2 & 0.0 & 0.0 & 0.0 & 0.0 & & 100.0 & 100.0 & 100.0 & 100.0 & 100.0 & 100.0 & 100.0 & 100.0 & 100.0 & 100.0 & 100.0 & 93.4 & 96.3 & 93.4 & 93.4 & 6 & CP034429.seq \\
\hline & 7 & 0.2 & 0.0 & 0.0 & 0.0 & 0.0 & 0.0 & & 100.0 & 100.0 & 100.0 & 100.0 & 100.0 & 100.0 & 100.0 & 100.0 & 100.0 & 100.0 & 93.4 & 96.3 & 93.4 & 93.4 & 7 & CP037926.seq \\
\hline & 8 & 0.2 & 0.0 & 0.0 & 0.0 & 0.0 & 0.0 & 0.0 & & 100.0 & 100.0 & 100.0 & 100.0 & 100.0 & 100.0 & 100.0 & 100.0 & 100.0 & 93.4 & 96.3 & 93.4 & 93.4 & 8 & CP045002.seq \\
\hline & 9 & 0.2 & 0.0 & 0.0 & 0.0 & 0.0 & 0.0 & 0.0 & 0.0 & & 100.0 & 100.0 & 100.0 & 100.0 & 100.0 & 100.0 & 100.0 & 100.0 & 93.4 & 96.3 & 93.4 & 93.4 & 9 & CP045768.seq \\
\hline & 10 & 0.2 & 0.0 & 0.0 & 0.0 & 0.0 & 0.0 & 0.0 & 0.0 & 0.0 & & 100.0 & 100.0 & 100.0 & 100.0 & 100.0 & 100.0 & 100.0 & 93.4 & 96.3 & 93.4 & 93.4 & 10 & CP046060.seq \\
\hline & 11 & 0.2 & 0.0 & 0.0 & 0.0 & 0.0 & 0.0 & 0.0 & 0.0 & 0.0 & 0.0 & & 100.0 & 100.0 & 100.0 & 100.0 & 100.0 & 100.0 & 93.4 & 96.3 & 93.4 & 93.4 & 11 & CP046061.seq \\
\hline & 12 & 0.2 & 0.0 & 0.0 & 0.0 & 0.0 & 0.0 & 0.0 & 0.0 & 0.0 & 0.0 & 0.0 & & 100.0 & 100.0 & 100.0 & 100.0 & 100.0 & 93.4 & 96.3 & 93.4 & 93.4 & 12 & CP050052.seq \\
\hline & 13 & 0.2 & 0.0 & 0.0 & 0.0 & 0.0 & 0.0 & 0.0 & 0.0 & 0.0 & 0.0 & 0.0 & 0.0 & & 100.0 & 100.0 & 100.0 & 100.0 & 93.4 & 96.3 & 93.4 & 93.4 & 13 & CP050324.seq \\
\hline & 14 & 0.2 & 0.0 & 0.0 & 0.0 & 0.0 & 0.0 & 0.0 & 0.0 & 0.0 & 0.0 & 0.0 & 0.0 & 0.0 & & 100.0 & 100.0 & 100.0 & 93.4 & 96.3 & 93.4 & 93.4 & 14 & CP050325.seq \\
\hline & 15 & 0.2 & 0.0 & 0.0 & 0.0 & 0.0 & 0.0 & 0.0 & 0.0 & 0.0 & 0.0 & 0.0 & 0.0 & 0.0 & 0.0 & & 100.0 & 100.0 & 93.4 & 96.3 & 93.4 & 93.4 & 15 & CP050334.seq \\
\hline & 16 & 0.2 & 0.0 & 0.0 & 0.0 & 0.0 & 0.0 & 0.0 & 0.0 & 0.0 & 0.0 & 0.0 & 0.0 & 0.0 & 0.0 & 0.0 & & 100.0 & 93.4 & 96.3 & 93.4 & 93.4 & 16 & CP050335.seq \\
\hline & 17 & 0.2 & 0.0 & 0.0 & 0.0 & 0.0 & 0.0 & 0.0 & 0.0 & 0.0 & 0.0 & 0.0 & 0.0 & 0.0 & 0.0 & 0.0 & 0.0 & & 93.4 & 96.3 & 93.4 & 93.4 & 17 & CP053028.seq \\
\hline & 18 & 5.3 & 5.5 & 5.5 & 5.5 & 5.5 & 5.5 & 5.5 & 5.5 & 5.5 & 5.5 & 5.5 & 5.5 & 5.5 & 5.5 & 5.5 & 5.5 & 5.5 & & 97.2 & 100.0 & 100.0 & 18 & CP053922.seq \\
\hline & 19 & 3.5 & 3.8 & 3.8 & 3.8 & 3.8 & 3.8 & 3.8 & 3.8 & 3.8 & 3.8 & 3.8 & 3.8 & 3.8 & 3.8 & 3.8 & 3.8 & 3.8 & 2.6 & & 96.1 & 96.1 & 19 & KF646784.seq \\
\hline & 20 & 5.3 & 5.5 & 5.5 & 5.5 & 5.5 & 5.5 & 5.5 & 5.5 & 5.5 & 5.5 & 5.5 & 5.5 & 5.5 & 5.5 & 5.5 & 5.5 & 5.5 & 0.0 & 2.6 & & 100.0 & 20 & LR134300.seq \\
\hline & \multirow[t]{2}{*}{21} & 5.3 & 5.5 & 5.5 & 5.5 & 5.5 & 5.5 & 5.5 & 5.5 & 5.5 & 5.5 & 5.5 & 5.5 & 5.5 & 5.5 & 5.5 & 5.5 & 5.5 & 0.0 & 2.6 & 0.0 & & 21 & \multirow[t]{2}{*}{ LR134309.seq } \\
\hline & & 1 & 2 & 3 & 4 & 5 & 6 & 7 & 8 & 9 & 10 & 11 & 12 & 13 & 14 & 15 & 16 & 17 & 18 & 19 & 20 & 21 & & \\
\hline
\end{tabular}

One colony of transformed cells was selected, sub-cultured in LB broth with ampicillin $(100 \mathrm{mg} / \mathrm{ml})$, and allowed to reach the OD of approximately 0.6 under shaking.

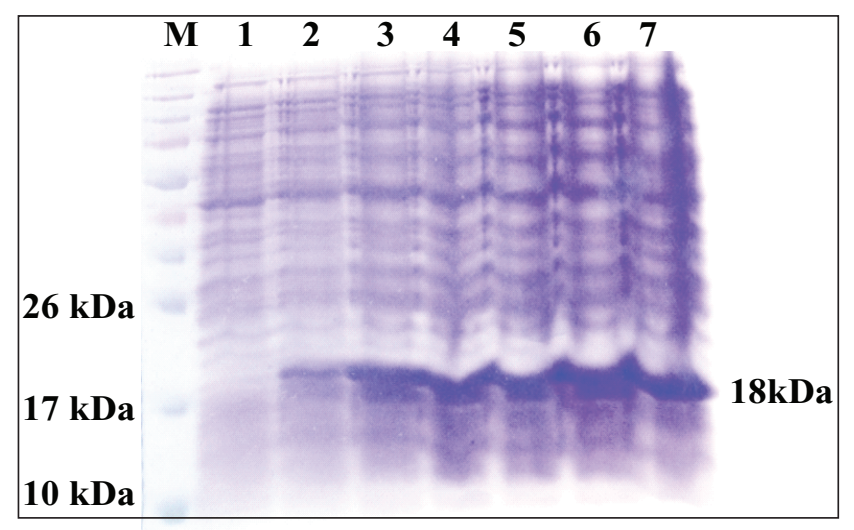

Fig. 5: SDS-PAGE analysis of expression level of recombinant protein. Lane 1: Protein molecular weight marker; Lane 2: Uninduced cell lysates; Lane 3, 4, 5, 6, and 7: induced cell lysates at various incubation time (1, 2, 3, 4, $6 \mathrm{~h}$ and overnight), respectively showing expression of E-Opr86 protein

Induction was done with $0.1 \mathrm{mM}$ IPTG, and samples were collected at hourly intervals up to $6 \mathrm{hrs}$ and after overnight shaking. Cells were pelleted out. SDS-PAGE detected the expressed protein, and an approximately $18 \mathrm{kDa}$ size band of expressed protein was detected after staining with coomassie brilliant blue. Expression kinetics studies indicated that the highest expression level was available at sixth hr post-induction (Fig. 5).

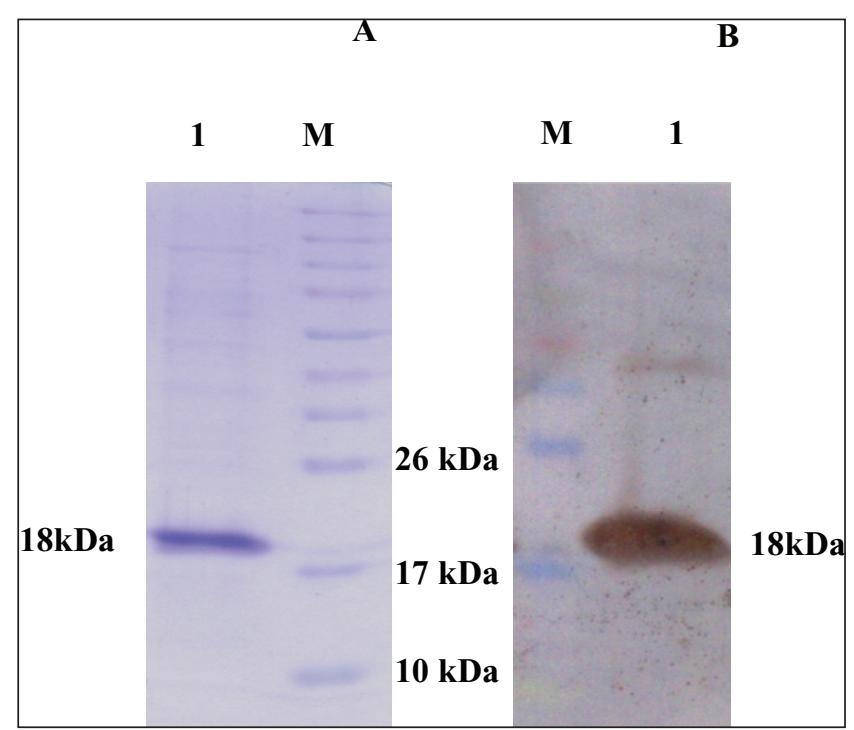

Fig. 6: Confirmation of purified recombinant protein by (A) SDS-PAGE analysis (Lane 1: molecular weight marker; Lane 2: purified protein) (B) Western blotting (Lane 1: purified protein; Lane 2: prestained protein molecular weight marker) 


\section{Purification of recombinant protein}

The purification of expressed recombinant protein was carried out by immobilized metal ion affinity chromatography (IMAC) using Ni-NTA affinity resin. The induced culture was collected and platted after 6 hrs, where the expression level was good. Then, the recombinant protein was purified using Ni-NTA affinity chromatography. SDS-PAGE and western blotting analysis of purified protein had a specific single band of approximately $18 \mathrm{kDa}$ (Fig. 6).

\section{DISCUSSION}

Despite significant developments in antimicrobial therapy, there are persistent problems for effective control and treatment of $P$. aeruginosa infections. As many studies showed intravenous injections of $P$. aeruginosa specific hyperimmune globulins having protective therapeutic intervention for $P$. aeruginosa infection (Sharma et al., 2011; van Wye et al., 1990), E-Opr86 protein can be used to raise of hyperimmune serum for passive immunization against $P$. aeruginosa infections. Moreover, Opr86 is an important protein of bacterium biofilm, antibody against Opr86 inhibits biofilm formation and E-Opr86 forms exposed outer domain of Opr86 (Tashiro et al., 2008). Therefore, recombinant E-Opr86 can be used in the future as a potential vaccine to prevent $P$. aeruginosa infection.

For expression study, the expression vector is the most critical factor to determine the expression level. pET series vectors are routinely used to express the heterologous protein in the prokaryotic system under the control of the T7 promoter, under which much integral protein has been expressed (Korepanova et al., 2009). In this study, pET302/NT-His expression vector was chosen to express recombinant protein E-Opr86 under control of T7 promoter and transformed into E. coli BL21 (DE3) pLysS Rosseta-gami 2 cells for a high level of expression. The pET302/NT-His Vector is used for high-level expression of recombinant protein with $\mathrm{N}$ - terminal 6xHis-tagged protein (Singh et al., 2015). The E. coli BL21 (DE3) pLysS Rosseta-gami 2 ease codon bias and enhance disulfide bond formation in the cytoplasm when heterologous proteins are expressed in E. coli (Chang et al., 2010).

In the current study maximum level of recombinant E-Opr86 expression in E. coli BL21 (DE3) pLysS Rosseta- gami 2 cells were detected at $6 \mathrm{hrs}$ post IPTG induction. A similar result has been reported for the maximum level of expression of OprL protein of $P$. aeruginosa at $\sim 6 \mathrm{hrs}$ post-induction (Young et al., 2012).

In this study, Ni-NTA affinity resin was used for the purification of the recombinant protein. The recombinant fused with Histidine tag (His-Tag) under denaturing condition with immobilized metal ion affinity chromatography (IMAC) using Ni-NTA affinity resin (Chang et al., 2010). The His-Tag is very useful as a fusion partner for protein purification as His-Tag has low immunogenicity and small size $(0.84 \mathrm{kDa})$. His-Tag fusion proteins can be affinity purified under denaturing conditions and native conditions. Ni-NTA exhibits a high affinity for histidine residues and allows elution of bound recombinant proteins by different ways such as an imidazole gradient (20 to $250 \mathrm{mM}$ ), changes in $\mathrm{pH}$, or metal chelation(Young et al., 2012). In the present study, the protein was purified under denaturing conditions and eluted at a pH of 4.5. On SDS-PAGE and western blotting, recombinant protein resulted in an intense color reaction at approximately $18 \mathrm{kDa}$, indicating the correct size of the expressed recombinant E-Opr86.

As pET302/NT-His Vector was used for expression purpose, the recombinant E-Opr86 protein obtained in this study have approximetly1.0 kDa of vector encoded HisTag and $17 \mathrm{kDa}$ of wild Opr86 protein.

This study confirmed that the gene encoding E-Opr86 protein is relatively conserved in various isolate of $P$. aeruginosa. High-level expression of recombinant E-Opr86 protein with minimum size vector encoded tag (approximetly $1 \mathrm{kDa}$ ) can be possible using pET302/ NT-His expression vector and E. coli BL21 (DE3) pLysS Rosseta-gami 2 cells. As Opr86 is essential for the viability of $P$. aeruginosa and antibody against it inhibits biofilm formation (Tashiro et al., 2008), the current study of E-Opr86 protein expression can pave the way to development subunit vaccine against $P$. aeruginosa.

\section{CONCLUSION}

$P$. aeruginosa E-Opr86 protein was successfully expressed in E. coli Rosetta-gami 2(DE3) pLysS cells using pET302/ NT-His expression vector. Purified recombinant E-Opr86 protein of approximately molecular weight $18 \mathrm{kDa}$ was 
confirmed by SDS-PAGE analysis and western blotting. In the future, recombinant E-Opr86 protein can be used as a vaccine candidate against $P$. aeruginosa infection.

\section{ACKNOWLEDGMENTS}

The authors thank the Director of Research, Guru Angad Dev Veterinary and Animal Sciences University (GADVASU), Ludhiana, for carrying out this research work and the financial support.

\section{REFERENCES}

Alhede, M., Bjarnsholt, T., Givskov, M. and Alhede, M. 2014. Pseudomonas aeruginosa biofilms. Mechanisms of immune evasion, In: Advances in Applied Microbiology, pp. 1-40. https://doi.org/10.1016/B978-0-12-800262-9.00001-9

Chang, H., Cheng, A., Wang, M., Zhu, D., Jia, R., Liu, F., Chen, Z., Luo, Q., Chen, X. and Zhou, Y., 2010. Cloning, expression and characterization of $\mathrm{gE}$ protein of Duck plague virus. Virol. J., 7: 120.

Furchtgott, L., Wingreen, N.S. and Huang, K.C. 2011. Mechanisms for Maintaining Cell-Shape in Rod-Shaped Gram-Negative Bacteria. Biophys. J., 100: 514a.

Hemamalini, R. and Khare, S., 2014. A proteomic approach to understand the role of the outer membrane porins in the organic solvent-tolerance of Pseudomonas aeruginosa PseA. PLoS One, 9: e103788.

Korepanova, A., Gao, F.P., Hua, Y., Qin, H., Nakamoto, R.K. and Cross, T.A. 2009. Cloning and expression of multiple integral membrane proteins from Mycobacterium tuberculosis in Escherichia coli. Protein Sci., 14: 148-158.

Pang, Z., Raudonis, R., Glick, B.R., Lin, T.J. and Cheng, Z., 2019. Antibiotic resistance in Pseudomonas aeruginosa: mechanisms and alternative therapeutic strategies. Biotechnol. $A d v$. https://doi.org/10.1016/j.biotechadv.2018.11.013
Remans, K., Vercammen, K., Bodilis, J. and Cornelis, P., 2010. Genome-wide analysis and literature-based survey of lipoproteins in Pseudomonas aeruginosa. Microbiology. https://doi.org/10.1099/mic.0.040659-0

Sambrook, J. and Russell, D.W. 2001. Molecular cloning: a laboratory manual (3-volume set). Mol. cloning a Lab. Man.

Sharma, A., Krause, A. and Worgall, S. 2011. Recent developments for Pseudomonas vaccines. Hum. Vaccin. https://doi.org/10.4161/hv.7.10.16369

Solanki, V., Tiwari, M. and Tiwari, V. 2019. Prioritization of potential vaccine targets using comparative proteomics and designing of the chimeric multi-epitope vaccine against Pseudomonas aeruginosa. Sci. Rep., 9.

Tashiro, Y., Nomura, N., Nakao, R., Senpuku, H., Kariyama, R., Kumon, H., Kosono, S., Watanabe, H., Nakajima, T. and Uchiyama, H. 2008. Opr86 is essential for viability and is a potential candidate for a protective antigen against biofilm formation by Pseudomonas aeruginosa. J. Bacteriol., 190: 3969-3978.

van Wye, J.E., Collins, M.S., Baylor, M., Pennington, J.E., Hsu, Y.P, Sampanvejsopa, V. and Moss, R.B. 1990. Pseudomonas hyperimmune globulin passive immunotherapy for pulmonary exacerbations in cystic fibrosis. Pediatr. Pulmonol., 9: 7-18.

Wu, M. and Li, X. 2014. Klebsiella pneumoniae and Pseudomonas aeruginosa, In: Molecular Medical Microbiology: Second Edition. pp. 1547-1564.

Young, C.L., Britton, Z.T. and Robinson, A.S. 2012. Recombinant protein expression and purification: A comprehensive review of affinity tags and microbial applications. Biotechnol. J., 7: 620-634.

Zhang, X., Yang, F., Zou, J., Wu, W., Jing, H., Gou, Q., Li, H., Gu, J., Zou, Q. and Zhang, J. 2018. Immunization with Pseudomonas aeruginosa outer membrane vesicles stimulates protective immunity in mice. Vaccine, 36: 1047-1054. 
